\title{
STAPHYLOCOCCUS AUREUS: PORTADORES ENTRE MANIPULADORES DE ALIMENTOS*
}

Maria Stella Gonçalves Raddi**

Clarice Queico Fujimura I.eite***

Clara Peckmann Mendonça**

\begin{abstract}
RADDI, M. S. G. et al. Staphylococcus aureus: portadores entre manipuladores de alimentos. Rev. Saúde públ., S. Paulo, 22:36-40, 1988.

RESUMO: Foram colhidas amostras de mãos e fossas nasais de 48 manipuladores de alimentos das principais casas comerciais da cidade de Araraquara, Estado de São Paulo (Brasil), e de 20 estudantes universitários. Dentre os indivíduos foram encontrados $44,1 \%$ e $34,8 \%$ que portavam Staphylococcus aureus em fossas nasais e mãos, respectivamente. Observou-se predomínio de fagotipos dos grupos I e III. Dos 12 portadores do microrganismo, concomitantemente em mãos e fossas nasais, $75,0 \%$ apresentaram cepas com vínculo epidemiológico. Os achados mostram o risco potencial representado pelas mãos nas intoxicaçōes alimentares.
\end{abstract}

UNITERMOS: Staphylococcus aureus, isolamento. Manipulação de alimentos. Portador. Intoxicação alimentar estafilocócica.

\section{INTRODUÇÃO}

Estudos de portadores de Staphylococcus aureus, com finalidade epidemiológica, vêm sendo realizados na tentativa de se estabelecer uma possível ligação entre $S$. aureus por eles albergados, sua disseminação e perpetuação de cepas resistentes que se propagariam no ambiente familiar ou de trabalho.

Surtos de intoxicação alimentar são freqüientemente relatados e os causados por Staphylococcus aureus são os mais comuns, pois havendo no alimento condições favoráveis à sua multiplicação, em poucas horas, certas cepas produzem uma toxina termoestável que é responsável pelo quadro clínico ${ }^{14}$. Os sintomas, que aparecem dentro de 1-6 horas após a ingestão do alimento, são caracterizados por náusea, vômito, espasmo abdominal e diarréia. Em casos severos, muco e sangue são observados no vômito e nas fezes. A intoxicação estafilocócica pode ser fatal para recém-nascidos e pessoas idosas.

As fossas nasais têm sido relatadas como a fonte mais importante de disseminação ${ }^{1,2,5}$, en- tretanto pouca atenção tem sido dada às mãos como fonte ou via de infecção.

A pele das mãos apresenta uma população de microrganismos que pode ser diferenciada em flora residente e flora transitória. A flora microbiana da pele pode ser reduzida pela lavagem com água e sabão ou detergente. Maki ${ }^{9}$, estudando a veiculação microbiana pelas mãos, verificou que $11 \%$ do pessoal amostrado transportava $S$. aureus, sendo este carreamento tipicamente transitório.

Os portadores nasais podem, por meio das mãos, desempenhar papel importante na disseminação do microrganismo, principalmente através dos alimentos por eles manuseados.

Partindo da hipótese que o principal reservatório de estafilococos no homem são as fossas nasais e na tentativa de mostrar a colonização das mãos pela mesma cepa presente nas fossas nasais, propusemo-nos a estudar amostras colhidas de mãos e fossas nasais de um grupo de manipuladores de alimentos de estabelecimentos comerciais da cidade de Araraquara, Estado de São Paulo.

* Elaborado com auxílio financeiro da Fundação de Amparo à Pesquisa do Estado de São Paulo (FAPESP). Proc. 85/0316-6. Apresentado no XIV Congresso Brasileiro de Farmácia e Bioquímica, Rio de Janeiro, 1986.

* Departamento de Análises Clínicas da Faculdade de Ciências Farmacêuticas da Universidade Estadual Paulista "Júlio de Mesquita Filho" (UNESP) - Rua Expedicionários do Brasil, 1621 14800 - Araraquara, SP - Brasil.

*** Departamento de Ciências Biológicas da Faculdade de Ciências Farmacêuticas da UNESP - Araraquara, SP - Brasil. 
Variações na microflora autóctone ao homem ocorrem de acordo com a área geográfica, nível socioeconômico, alimentação, hábitos de higiene e outros fatores que modificam a susceptibilidade do hospedeiro. Com o objetivo de comparação, amostramos também um grupo constituído por estudantes universitários onde presumimos ser apenas a área geográfica o fator comum a ambas populações.

\section{MATERIAL E METODOS}

Após tratamento estatístico, realizou-se a coleta de material de fossas nasais e mãos de 48 manipuladores de alimentos dos principais estabelecimentos comerciais de Araraquara-SP e de um grupo composto por 20 estudantes da Faculdade de Ciências Farmacêuticas de Araraquara-UNESP, que se denominou grupocontrole.

As amostras foram obtidas concomitantemente, em dois dias consecutivos, das duas áreas anatômicas. $\mathrm{O}$ material de fossas nasais foi colhido através de zaragatoa e mantido em caldo tripticase soja (TSB). Para a amostragem das mãos utilizou-se, com modificações, a técnica do saco plástico proposta por Gaschen ${ }^{4}$, onde u'a mão e após, a outra foi lavada em luva descartável (Profilax) contendo $10 \mathrm{ml}$ de caldo tripticase soja durante $1 \mathrm{~min}$.

Os caldos foram incubados por $24 \mathrm{~h}$ a $37^{\circ} \mathrm{C}$. Após esse período fez-se o isolamento em agar sangue azida e meio de Chapman. As colônias suspeitas de pertencerem a estafilococos foram caracterizados seguindo a metodologia descrita por Blair ${ }^{3}$ e Kloos e Smith ${ }^{7}$.

As amostras coagulase-positiva foram submetidas à fagotipagem, frente aos fagos do conjunto básico internacional: Grupo I - 29, $52,52 \mathrm{~A}, 79$ e 80; Grupo II - 3A, 3C, 55 e 71; Grupo III - 6, 42E, 47, 53, 54, 75, $77,83 \mathrm{~A}, 84$ e 85 ; Não classificados -81 , 94, 95 e 96; Fagos experimentais - 86, 88, 89, 90, 92, $\mathrm{D}_{11}$ e $\mathrm{HK}_{2}$; Fagos extras - 42D e 187; utilizando-se duas diluições diferentes dos fagos: 1 x RTD (diluição de rotina) e $100 \times$ RTD para as amostras que não reagiram com a primeira diluição*.

\section{RESULTADOS}

Dentre os manipuladores analisados, $62,5 \%$ (30) albergavam $S$. aureus independente da área anatômica amostrada e para o grupo- controle a taxa de portadores foi de $55,0 \%$ (11) em mãos e/ou fossas nasais. A Tabela 1 mostra a distribuição das amostras isoladas nos dois grupos estudados. Verificamos a presença do microrganismo concomitantemente em mãos e fossas nasais em $20,8 \%$ (10) indivíduos pertencentes ao grupo dos manipuladores e em 10,0\% (2) pertencente ao grupocontrole.

\section{TABELA 1}

Distribuição dos Staphylococcus aureus isolados dentro dos grupos analisados segundo a origem da amostra. Araraquara, SP, 1985.

\begin{tabular}{lccccc}
\hline \multirow{2}{*}{ Grupo } & \multicolumn{4}{c}{ Área anatômica } \\
\cline { 2 - 3 } \cline { 2 - 3 } & \multicolumn{2}{c}{ FN* } & & \multicolumn{2}{c}{ M $^{* *}$} \\
\cline { 2 - 3 } \cline { 5 - 7 } & N. & $\%$ & & N. & $\%$ \\
\hline Manipuladores (48) & 20 & 41,7 & & 20 & 41,7 \\
Controle (20) & 10 & 50,0 & & 3 & 15,0 \\
Total (portadores) & 30 & 44,1 & & 23 & 33,8 \\
\hline
\end{tabular}

* Fossas Nasais

** Mãos

A Tabela 2 mostra os resultados da fagotipagem das amostras de $S$. aureus isoladas. A diluição de rotina ( 1 x RTD) permitiu a caracterização de 41 amostras e o emprego da diluição 100 x RTD de 5 das 12 amostras restantes. Observou-se que a maioria das amostras foram classificadas nos grupos fági$\cos$ I, III e I + III.

\section{TABELA 2}

Distribuição dos grupos fágicos obtidos nas amostras de Staphylococcus aureus isolados dentro dos grupos estudados. Araraquara, SP, 1985.

\begin{tabular}{lrrrrrr}
\hline & \multicolumn{2}{c}{$\begin{array}{c}\text { Manipu- } \\
\text { ladores }\end{array}$} & Controle & \multicolumn{2}{c}{ Total } \\
\cline { 2 - 7 } & FN & M & FN & M & N. $^{\circ}$ & $\%$ \\
\hline I & 4 & 5 & 2 & 1 & 12 & 22,60 \\
II & 1 & 1 & & 1 & 3 & 5,70 \\
III & 5 & 6 & 1 & 1 & 13 & 24,50 \\
I + III & 4 & 3 & 1 & & 8 & 15,10 \\
I + III + NC* & 2 & 1 & 1 & & 4 & 7,55 \\
I + NC & & 1 & & & 1 & 1,90 \\
Experimental & 1 & 1 & 2 & & 4 & 7,55 \\
Não classificados & 1 & & & & 1 & 1,90 \\
Não tipável & 2 & 2 & 3 & & 7 & 13,20 \\
\hline Total & 20 & 20 & 10 & 3 & 53 & 100 \\
\hline
\end{tabular}

* Não classificado.

* Realizado no Laboratório de Fagotipagem da Faculdade de Medicina de Ribeirão Preto, Estado de Säo Paulo. 
Considerando-se a fagotipagem em portadores de $S$. aureus concomitantemente em mãos e fossas nasais, o que é de fundamental importância para a conclusão de nosso trabalho, observou-se que as amostras de ambos os sítios provenientes de M-6, M-31, M-32, M-34, $\mathrm{M}-47, \mathrm{C}-20$ são idênticas, assim como as provenientes de M-2, M-42 e C-21 também devem ser consideradas idênticas pelo vínculo epidemiológico apresentado (Tabela 3).

\section{TABELA 3}

Distribuição das amostras de $S$. aureus isoladas concomitantemente em fossas nasais e mãos segundo a fogotipagem de ambos os grupos amostrados. Araraquara, 1985.

\begin{tabular}{ll}
\hline Amostra & \multicolumn{1}{c}{ Fagotipo } \\
\hline FNM* - & $29 / 52 \mathrm{~A} / 79 / 53 / 83 \mathrm{~A} / 85$ \\
MM** - & $29 / 53 / 83 \mathrm{~A} / 85$ \\
FNM - 6 & 29 \\
MM - 6 & 29 \\
FNM - 18 & $\mathrm{NT}$ \\
MM - 18 & $\mathrm{D} 11$ \\
FNM - 24 & $\mathrm{NT}$ \\
MM - 24 & NT \\
FNM - 26 & $42 \mathrm{E}$ \\
MM - 26 & $29 / 52$ \\
FNM - 31 & $29 / 52 / 52 \mathrm{~A} / 83 \mathrm{~A}$ \\
MM - 31 & $29 / 52 / 52 \mathrm{~A} / 83 \mathrm{~A}$ \\
FNM - 32 & 29 \\
MM - 32 & 29 \\
FNM - 34 & $52 \mathrm{~A}$ \\
MM - 34 & $52 \mathrm{~A}$ \\
FNM - 42 & $29 /+$ \\
MM - 42 & $29 / 95 /+$ \\
FNM - 47 & $42 \mathrm{E}$ \\
MM - 47 & $42 \mathrm{E}$ \\
FNC*** - 20 & $29 / 80$ \\
MC**** 20 & $29 / 80$ \\
FNC - 21 & $42 \mathrm{~A} / 83 \mathrm{~A}$ \\
MC - 21 & $42 \mathrm{~A} / 47 / 83 \mathrm{~A} / 85$ \\
\hline
\end{tabular}

* Fossas nasais do manipulador.

* Mãos do manipulador.

*** Fo:sas nasais do controle.

**** Mãos do controle.

\section{DISCUSSÃO}

O principal reservatório de estafilococos no homem são as fossas nasais e a incidência na população é tal que parece ser impossível sua eliminação. Segundo Morse"1, a taxa de portadores intermitentes adultos pode atingir $50 \%$. Nossos resultados, no que se refere ao percentual de portadores nasais das populações estudadas, cujos índices alcançaram 50\% para grupo-controle e $41,7 \%$ para o dos manipuladores, encontram-se acima da faixa observada por outros pesquisadores em população extra hospitalar. Millian e col..$^{10}$ estudaram a presença de $S$. aureus em manipuladores de alimentos e constataram que $38 \%$ deles eram portadores em fossas nasais. Iaria ${ }^{5}$ (1976), detectou $35,2 \%$ de portadores em pessoas que trabalhavam em cozinhas de três hospitais do Município de São Paulo. Os fatores que controlam a dinâmica do estado de portador ainda são obscuros.

Os portadores nasais podem, através das mãos, contaminar a pele em uma frequiência digna de nota ${ }^{2}$. Esse fato pode ser evidenciado quando observamos a população que alberga Staphylococcus aureus em mãos e fossas nasais, sugerindo uma contaminação à partir das próprias fossas nasais, objetos por eles manuseados ou mesmo uma fonte externa representada principalmente por indivíduo doente ou portador.

Tendo as mãos como veículo de trabalho, os manipuladores de alimentos podem, através do contato direto ou por perdigotos, perpetuar a cadeia epidemiológica da intoxicação alimentar estafilocócica. Esse fato já está documentado e há evidências de sua importância na epidemiologia das diarréias ${ }^{12}$.

Observamos maior frequiência de portadores de $S$. aureus em mãos, no grupo dos manipuladores $(41,7 \%)$, quando comparado aos do grupo-controle $(15 \%)$. Esse fato é explicado por Woodroffe e Shaw ${ }^{17}$ que aceitam o fator umidade como sendo primário para a multiplicação de bactérias na pele. Concordando com nossos resultados, Lowburg ${ }^{8}$ comenta que os $S$. aureus podem se estabelecer como germes residentes da flora das mãos em indivíduos que trabalham persistentemente em contato com água.

Analisando os fagotipos encontrados nas amostras, verificamos a prevalência dos tipos I, III e I + III $(62,2 \%)$. A susceptibilidade aos fagos em várias oportunidades pode ser associada a outras características biológicas dos estafilococos. Geralmente membros do grupo II provocam lesões esfoliativas de pele; cepas que causam surtos hospitalares estão associados ao grupo $\mathrm{I}^{16}$.

Apesar das tentativas, a relação entre a fagotipagem e a capacidade enterotoxigênica do $S$. aureus ainda não está definida. A maioria das cepas produtoras de intoxicação alimentar tem se revelado aos fagos do grupo III $^{6}$. Simkovicova e Gilbert ${ }^{13}$ e Wieneke ${ }^{15}$ ve- 
rificaram que comumente são isoladas cepas de $S$. aureus associadas a surtos de intoxicação alimentar sensíveis a fagos dos grupos IIl e I + III.

O objetivo principal dessa pesquisa é verificar se um mesmo indivíduo pode estar colonizado nas áreas estudadas (FN e M) pela mesma cepa de $S$. aureus, o que nos é permitido concluir unicamente por meio da fagotipagem.

Considerando o fato que dos 12 portadores de $S$. aureus, concomitantemente em mãos e fossas nasais, $9(75,0 \%)$ possuíam cepas com vínculo epidemiológico, nossos resultados sugerem possibilidade de que a via de contaminação das mãos sejam as fossas nasais. Assim as observações evidenciam o risco potencial representado por fossas nasais contaminadas entre os manipuladores de alimentos.

Embora a contaminação das mãos seja de fundamental importância na transmissão de microrganismos patogênicos, vários trabalhos enfatizam a necessidade da lavagem adequada considerando-a como procedimento único mais importante na prevenção das infecções por elas veiculadas.

Assim, conforme evidenciamos no presente trabalho, o carreamento de $S$. aureus pelas mãos pode representar um papel importante na cadeia epidemiológica das intoxicaçōes alimentares. Tradicionalmente, as medidas de controle incluem a implementação de técnicas de lavagem das mãos, treinamento e conscientização dos profissionais envolvidos. Nossa expectativa é que esse trabalho venha contribuir de forma significativa para melhor conhecimento do problema e que medidas sejam tomadas visando reduzir o número de intoxicaçōes alimentares por Staphylococcus aureus.

\section{CONCLUSÕES}

Os resultados obtidos permite-nos apresentar as seguintes conclusões:

1 - Em 48 indivíduos que manipulam alimentos e estudantes universitários, a proporção de portadores nasais de Staphylococcus aureus foi de $41,7 \%$ e $50,0 \%$, respectivamente, taxas consideradas altas.

2 - A percentagem de portadores de $S$. aureus nas mãos foi mais alta para 0 grupo dos manipuladores $(41,7 \%)$ quando comparada ao grupo-controle $(15,0 \%)$.

3 - Doze portadores albergavam simultaneamente o microrganismo nas fossas nasais e mãos.

4 - Evidenciou-se predomínio de fagotipos pertencentes aos grupos I e III.

5 - Em 9 portadores a fagotipagem revelou vínculo epidemiológico entre as duas amostras ( $\mathrm{FN}$ e $\mathrm{M}$ ).

\section{AGRADECIMENTOS}

Ao Prof. Dr. Edmundo Juarez e sua equipe, do Serviço Especial de Saúde de Araraquara, pela realização do tratamento estatístico e participação na coleta de amostras. À Profa. Dra. Maria Utida-Tanaka e sua equipe, da Faculdade de Medicina de Ribetirão Preto - USP, pela realização da fagotipagem.

RADDI, M. S. G. et al. [Staphylococcus aureus: food handler carriers]. Rev. Saúde públ., S. Paulo, 22:36-40, 1988 .

ABSTRACT: Material was collected from the hands and nasal passages of forty-eight food handlers and twenty college students of Araraquara (S. Paulo State, Brazil) and analized in order to evaluate the carrier function with regard to Staphylococcus aureus. The organism discovered in both samples of nine out of the twelve volunteers were of the same $S$. aureus phage types. The incidence of carriage on the hands was much greater in the handlers' group. These findings demonstrate the potential risk represented by hands in the transmission of food poisoning.

UNITERMS: Staphylocaccus aureus, isolation. Food handling. Carrier state. Staphylococcal food poisoning. 


\section{REFERENCIAS BIBLIOGRÄFICAS}

1. ARAUJO-ARANTES, M. A.; UTHIDA-TANAKA, A. M.; CASTRO, O. C. Staphylococcus aureus: prevalência de portadores extra-hospitalares (restaurantes) na cidade de Ribeirão Preto, SP (1981). Medicina, Ribeirão Preto, 15:225-32, 1982.

2. ARAUJO-ARANTES, M. A.; LIMA, E. G.; CASTRO, O. C. Prevalência de portadores de Staphylococcus aureus entre trabalhadores de uma fábrica de produtos alimentícios. Rev. goiana Med., 28:151-8, 1982.

3. BLAIR, J. E. Laboratory diagnosis of staphylococcal infections. Bull. Wld Hlth Org., 18: 291-397, 1958.

4. GASCHEN, M. Etude comparative de deux méthodos destinees au prélèvement de la flore microbienne des mains. Helv. chir. Acta, 35:372-7, 1968.

5. IARIA, S. T.; FURLANETTO, S. M.; CAMPOS, M. L. Pesquisa de Staphylococcus aureus enterotoxigênico nas fossas nasais de manipuladores de alimentos em hospitais, São Paulo, 1976. Rev. Saúde públ., S. Paulo, 14: 93-100, 1980.

6. JAY, M. J. Microbiologia moderna de los alimentos. Zaragoza, Ed. Acribia, 1973.

7. KLOOS, W. E. \& SMITH, P. B. Staphylococci. In: Lanette, E. H., ed. Manual of clinical microbiology. 4th ed. Washington, D. C. American Society for Microbiology, 1985. p. 143-53.

8. LOWBURG, E. J. L. Special problems in hospital antisepsis. In: Russel, W. H. \& Ayliffe, G. A., eds. Principles and practice of desinfection, preservation and sterilization. Oxford, Blackwell Scientific Publ., 1982. p. 262-4.

9. MAKI, D. G. Control of colonization and transmission of pathogenic bacteria in the hospital. Ann. intern. Med., 89:777-80, 1978.
10. MILLIAN, S. J. Studies on incidence of coagulase positive staphylococci in a normal unconfined population. Amer. J. publ. Hlth, 50:791-98, 1960.

11. MORSE, S. I. Staphylococci. In: Davis, B. D., ed. Microbiology, 3rd ed. Philadelphia, Harper International Edition, 1980. p. 624-33.

12. ROBINS-BROWNW, R. M. A hospital outbreak of multiresistant Salmonella typhimurium belonging phage type 193. J. infec. Dis., 147:210-6, 1983

13. SIMKOVICOVA, M. \& GILBERT, R. J. Serological of enterotoxin from food-poisoning strains of Staphylococcus aureus. J. med. Microbiol., 4:19-30, 1971.

14. TROLLER, J. A. Effect of water activity on enterotoxin production and growth of Staplyylococcus aureus. Appl. Microbiol, 21:435-9, 1971.

15. WIENEKE, A. A. Enterotoxin prodution by strains of Staphylococcus aureus isolated from foods human beigs. J. Hyg., London, 73: 255-62, 1974.

16. WILSON, G. S. Principles of bacteriology, virology and immunology. 6th ed. Philadelphia, Lea \& Febiger, 1984.

17. WOODROFFE, R. C. S. \& SHAW, D. A. Natural control and ecology of microbial populations on skin and hair. In: Skinner, F. F. \& Carr, J. A., eds. The normal microbial flora of man. London, Academic Press, 1978. p. 13-34.

Recebido para publicação em: 6/4/1987 Reapresentado em: $15 / 10 / 1987$

Aprovado para publicação em: 16/11/1987 